\title{
Service intermediation as a concept for an institutional publishing department
}

\author{
Fabian Cremer and Katrin Neumann
}

\section{Research organizations and their policies and repositories}

1 After the Budapest, Berlin and Bethesda (BBB) declarations, many research organizations pursued the adoption of an Open Access policy. In Germany, about half of the universities had implemented an Open Access policy by 2016 (Wohlleben 2016, 13) with a steady rise of up to roughly 75\% now (ROARMAP 2018). Almost all of the universities and research institutions with an Open Access policy host an institutional repository to deposit publications. However, only a few universities host their own university presses. It seems research organizations tend to act as policy makers in the Open Access movement, but hesitate to be more actively involved in the publishing process by providing services and infrastructure for publishing. As Fitzpatrick has pointed out, university administrations care more about the evaluation of research and not about its dissemination. But, Fitzpatrick further argues, if scholarly organizations recognize the dissemination of scholarship as a valuable part of their core mission, these organizations must take responsibility for the publication process (Fitzpatrick 2009, Ch. 5). This article reflects on a services concept of an editorial department of a research institute that may serve as an example for a more active involvement of research institutions in the publication process through acting as an intermediary between authors, editors, infrastructures, and the publishing houses as well as their own administration. 


\section{The publication landscape of the Max Weber Foundation}

The Max Weber Foundation maintains ten autonomous research institutes, which are fully autonomous in their research activities, and several offices around the world. Undertaking research in the humanities and social sciences, the institutes focus on history, culture, economic and social sciences and promote a mutual understanding between Germany and its host countries. Institutionally financed by the public sector as a research organization, the Max Weber Foundation is committed to the principles of Open Access and maintains the online publication platform perspectivia.net since 2008.

While being one of the smaller research institutions in Germany compared to universities and the very large associations of Helmholtz and Max Planck, which are also two of the main drivers in Open Access, the Max Weber Foundation operates globally and highly networked due to its decentralized structure. The foundation provides a central framework for its nodes and, as a result, is dealing and operating in multiple national and international publication landscapes, which are diverse and heterogeneous themselves:

- Multiple Roles: In addition to the research output from the fellowships and various grants, the institutes publish their own journals and book series.

- Multilingual: The research results are written in German and in the local language as well as in the leading languages of the various disciplines.

- Binational: As the host countries and Germany are both subjects of the research topics, also both national/lingual research communities and publication audiences have to be addressed, often separately.

- Cooperations: The publishing activities of the institutes are often conducted in cooperation with traditional publishers, both in Germany and the host countries.

- Decentralized: Each institute operates its publication activities autonomously, with own staff and different scopes.

- Formats: In addition to monographs and edited volumes, as well as journal articles, the publication formats include working papers, reviews, lectures, blogs, digitized sources and Digital Editions.

While there are many activities to foster exchange of knowledge and technology, there are no intentions to consolidate this heterogeneous environment in general or to reduce actors, language or formats. The diversity and individual approaches are crucial for conducting the humanities research in multiple countries and disciplines. The Max Weber Foundation values the reliable structures, the cultural tradition and the innovative potential ensured through the diversity of the actors in these publishing landscapes and therefore supports the Jussieu Call for Open science and bibliodiversity (Jussieu Call 2017).

\section{From information intermediary to service intermediary}

5 It is a commonplace, that the digital transformation of scholarly communication disrupts the once well-defined and commonly understood roles, responsibilities and capabilities of the actors in the publishing system: authors, publishers, libraries and readers. A crucial factor in the transition to digital scholarship is the massive amount of potentially 
available information and the resulting problems of scale for retrieval and management (Borgman 2000, 25-26). As a solution for the "information overload" Rose suggest an (commercial) agent, who acting on behalf of "end-users": the information intermediary (Rose 1999, 76-82). In a study with a broader concept, which includes non-profit approaches, Womack describes the general role of an information intermediary: “Thus, an information intermediary can be viewed as any system that mediates between the producers and consumers of information" (Womack 2002, 133). In the traditional scholarly communication there are two main information intermediaries: publishers and libraries. Their tasks can be described as gathering, selecting, enhancing, and informing (Day 1995).

6 However, as technical, economic and regulatory frameworks have deranged the traditional ecosystem, "the boundaries between authors, publishers, libraries, and information consumers are being blurred as each group stakes out new territory in the electronic information landscape" (Womack 2002, 130). Although communication technologies and information infrastructures are leading to the obsolescence of print publishers and library book stacks, the main effect of the digital transformation on the publication market has to be characterized as re-intermediation rather than disintermediation. Large commercial publishers were able to keep their dominant market position, due using their exclusive rights to information: The shift to database subscription models, instead of selling copies, removed ownership from the readers; creating bundles of information prevented end-user-driven buying, and additional services and infrastructure created publisher-controlled ecosystems. "The highly concentrated supply side faces a highly fragmented buy side, primarily academic institutions" (Ponte et al. 2017, 98), and as a result, led to significant price increases. In opposition to the oligopoly of the large publishing houses and the concepts of service bundling or cornering the market, a decent amount of public institutions, non-profit initiatives or small businesses offer services for the publication process. These services are specialized and also satisfy niches or offer transparent and privacy compliant alternatives to popular commercial services. Though, this highly fragmented supply side creates an unclear offer of suppliers confusing the buy side.

7 In the social sciences and humanities the publication landscape in general is more fragmented (OPERAS 2017) and less dependent of large publishers (because it is less attractive) compared to sciences (Larivière et al. 2015). However, humanities researchers or research organizations are not more familiar dealing with a complex publishing landscape, as their individual (or disciplinary) landscape is defined by the prestigious series and journals in the same way as in the sciences. Moreover, technology, infrastructures and practices of Open Access, such as preprint servers (and preprint culture) are adopted much slower and with lesser impact. This change process is determined by the intermediated communication between authors and readers, because authors may not take over all the tasks of the information intermediaries-as this example illustrates:

Authors often provide coarse topical categorization on their personal Web sites or add a few keywords to conference papers, but few are willing to catalog their entire oeuvre in a specified format whether for a promotion review or contribution to an institutional repository. (Borgman 2007, 25)

8 The information intermediary adds value by providing expertise and saving time. In order to add value, a diverse publication landscape needs a complete re-intermediation of 
the traditional mediation between the end-users (authors and readers) implemented in print age. A heterogeneous, decentralized, fragmented and specialized publishing landscape is first and foremost confusing for the authors and thus creating a demand for consulting-or additional intermediation. Here, the subject of intermediation is not information, but the services provided by the different information intermediaries.

\section{Building a services portfolio through partnerships}

Despite having a rather undefined Open Access policy, the Max Weber Foundation has invested in digital publishing relatively early. From the very beginning perspectivia.net has promoted open HTML-based publications and has been very successful in the formats of review journals and working papers for a decade now (Landes 2009 and Cremer/Neumann 2018). However, in that decade the transformation processes in digital publishing led to multiple change processes in infrastructure, staff and mission of perspectivia.net. Its three core tasks are now to serve as an institutional repository, to offer professional digital publishing services and to provide a competence center for digital publishing and research data management. Despite operating with a very small staff and without its own information infrastructures, the portfolio includes journals, series, monographs, secondary publications (green Open Access), blogs, multimedia, digitization and research data while supporting HTML-Presentation and XML-Workflows, Referencing, Cataloguing, Indexing, rights management and even print. The goal is to offer a comprehensive but optional support through consulting, assistance and management and acting as a broker. In order to offer such a large portfolio, the editorial team built its services concept on partnerships, cooperations and outsourced services on various levels (see also Cremer/ Heinemann 2017).

10 In the network of partners for digital publication, the traditional information intermediaries, libraries and publishers, still play the most important role, but with different tasks and responsibilities. The central service unit of a large German library coalition (Gemeinsamer Bibliotheksverbund) hosts the central repository of perspectivia.net. The repository software (MyCoRe) is collaboratively developed by a community of academic institutions, mostly university libraries. The Bavarian State Library provides metadata expertise and cataloging of the publications. The Heidelberg University Library provides expertise for innovative digital publishing technologies and workflows and hosts the journal infrastructure of perspectivia.net based on OJS. Different university libraries secure discipline-specific literature dissemination. Monographs are published both with university presses (e.g. HeiUP [Heidelberg University Press]) as well as with larger commercial publishers (e.g. V\&R [Vandenhoeck \& Ruprecht]), in Open Access and closed, print and online.

11 In addition to the traditional information intermediaries, cooperations with infrastructure service providers add to the portfolio, such as a university computing center (GWDG) provides both basic and advanced IT infrastructure and services. The national and European infrastructure consortia DARIAH and CLARIN provide crucial components of a digital humanities research infrastructure. But most important are the knowledge networks, which create the necessary expertise for conducting state-of-theart digital publishing. Established meetings with similar institutions or other projects serve as networks for exchange and reflection. The OPERAS research infrastructure 
consortium enables knowledge and technology exchange as well as shared developments and project partnerships.

The main tasks of the digital publication department are to maintain and expand the partnerships and networks, to expose services to their respective target audiences, such as discipline-specific repositories to authors, and to hide services and tasks, which are traditionally not conducted by them, such as metadata and infrastructure. Making a highly diverse landscape less confusing, service intermediation includes both, exposure and disclosure.

\section{Service intermediation as a publication practice}

The editorial team of perspectivia.net tries to fill the role as an intermediary between the different actors in the publishing sector and adds own tasks to fill in possible gaps in the process. Four examples:

1. Even for information professionals it is a complex task to keep track of all publishing services and their conditions offered by the different libraries and the research data services by larger infrastructures providers. The editorial team seeks to keep an overview and filter the information for the researchers, as well as distribute and promote the services from the providers.

2. Every step towards more openness is encouraged and supported, also when it does not comply with Open Access standards. If one of the large companies is the desired publisher, no efforts are made to convince the researcher to publish Open Access. Instead, we try to convince the publisher to a secondary publication and handing over a digital format suitable for archiving. The resulting moving walls, restricted licenses and exclusive content may not be desirable, but at least openly accessible.

3. Most publishers may offer the author a PDF via their homepage, but they will not create a searchable record for scholarly (and Open Access) search engines nor a professionally enriched library catalogue entry nor an archivable format such as PDF/A or XML. The institutional repository from the organization, the subject librarian from the cooperating library and the data management of the editorial team will perform these tasks - as an addition to the publisher's service offer.

4. Innovative formats or new ways of scholarly communication are neither created nor supported by the established publishing industry. The perspectivianet team includes a national community management for academic blogs from the Open Edition infrastructures hypotheses.org, acting as an intermediary between the French infrastructure provider and a German research community.

14 Service intermediation may imply different layers of involvement: exposure of information on services, selecting a certain service for an actor, active moderation of communication between two actors, take over full responsibility for a task, and offering own services to fill out gaps on the supply side. 


\section{Service intermediation as an organizational challenge}

As the digital editorial department of perspectivia.net in general is open for many forms of cooperation, which includes large players from the publishing industry, there are a few principles that will not be sacrificed and some best practices:

- If perspectivia.net invests in infrastructure (as our repository software and its maintenance) it is based on Open Source software and maintained by an academic non-profit institution.

- If we invest workforce in preparing a publication (transformation, editing, etc.), there has to be a freely available version, preferably open definition compatible.

- Our goal is to facilitate, not being a gatekeeper. If researchers and publishers communicate well bilaterally, the editorial team remains in the background.

- The digital transformation requires continuous change management, every slow step is embraced.

- The digital editorial department seeks to complement the other actors in publishing, not to compete with them.

Building services on third-party relationships provides a challenge for both, coordination and sustainability, of the services portfolio. To tackle these issues, perspectivia.net relies on concepts for network sustainability which includes defined leadership, multiple communication paths in larger networks, and shared goals (Heinemann 2018). Commitment from higher management and financial backup is also a prerequisite. Having at least one alternative partner for certain services is also crucial to prevent stagnation, but also for sharing the work. The basis for the publishing and research services, which perspectivia.net has implemented, is a vital and diverse landscape of players and actors with different scopes and competences. Protecting the diversity in the publishing sector requires joint forces between multiple players such as institutions and their libraries, initiatives and small businesses. This adds a communication and management layer, which has to be taken care of by one the stakeholders. As researchers are already overloaded with administrative tasks and small businesses are pressured by the market, research organizations and their own administrations and libraries may find themselves in this position. While they may interpret this as a burden and hesitate to get involved, we as a research organization see this as a chance to provide a valuable service for researchers in the humanities and step up as an actor, enriching the publishing landscape ourselves.

\section{BIBLIOGRAPHY}

\section{References}

Borgman, Christine L. 2010. From Gutenberg to the Global Information Infrastructure: Access to Information in the Networked World. Cambridge, Mass: Gb. 
Borgman, Christine L. 2007. Scholarship in the Digital Age: Information, Infrastructure, and the Internet. Cambridge, Mass: MIT Press.

Cremer, Fabian, and Elisabeth Heinemann. 2017. "In Zukunft verbunden. Digitale Infrastrukturen für die Forschung." Wissen in Verbindung (blog), November 23. https://mws.hypotheses.org/39412

Cremer, Fabian, and Katrin Neumann. 2018. "Zurück in die Zukunft II - keine erweiterten Publikationen in den Geisteswissenschaften?” Digitale Redaktion (blog), July 18. https:// editorial.hypotheses.org/231.

Day, Colin. 1995. “Economics of Electronic Publishing." Journal of Electronic Publishing 1 (1-2). http://dx.doi.org/10.3998/3336451.0001.111.

Fitzpatrick, Kathleen. 2009. Planned Obsolescence: Publishing, Technology, and the Future of the Academy. MediaCommons Press. http://mcpress.media-commons.org/plannedobsolescence/.

Heinemann, Elisabeth. 2018. "The Value of Network Sustainability: Why We Join Research Infrastructures." In ELPUB 2018, edited by Leslie Chan and Pierre Mounier. Toronto, Canada. https://doi.org/10.4000/proceedings.elpub.2018.22.

Landes, Lilian. 2009. “Open Access und Geschichtswissenschaften." LIBREAS. Library Ideas 14 (April 7): 26-30. http://dx.doi.org/10.18452/8918.

Larivière, Vincent, Stefanie Haustein, and Philippe Mongeon. 2015. "The Oligopoly of Academic Publishers in the Digital Era." PLoS ONE 10, (6): e0127502. https://doi.org/10.1371/ journal.pone.0127502.

OPERAS Consortium. 2017. "Landscape Study on Open Access Publishing - Annex to OPERAS Design Study.” Zenodo, October 12. https://doi.org/10.5281/zenodo.1009554.

Ponte, Diego, Bozena I. Mierzejewska, and Stefan Klein. 2017. "The Transformation of the Academic Publishing Market: Multiple Perspectives on Innovation.” Electronic Markets 27, no. 2 (May 1): 97-100. https://doi.org/10.1007/s12525-017-0250-9.

ROARMAP: Registry of Open Access Repository Mandates and Policies. 2018. https:// roarmap.eprints.org/.

Rose, Frank. 1999. The Economics, Concept, and Design of Information Intermediaries: A Theoretic Approach. Information Age Economy. Physica-Verlag Heidelberg. https://www.springer.com/de/ book/9783790811681.

Wohlleben, Verena. 2016. “Open-Access-Policies Staatlicher Hochschulen: Eine Bestandsaufnahme.” Report, March 1. http://eprints.rclis.org/29000/.

Womack, Ryan. 2002. "Information Intermediaries and Optimal Information Distribution." Library \& Information Science Research 24, no. 2 (January 1): 129-55. https://doi.org/10.1016/S0740-8188 (02)00109-3.

\section{ABSTRACT}

The service portfolio of the institutional publishing platform perspectivia.net is built on partnerships, cooperations, and community networks. The paper discusses context, preconditions, best practices and challenges of an institutional service concept relying on services outside the institution. 
INDEX

Keywords: Publishing services, institutional repository, social sciences and humanities

\section{AUTHORS}

\section{FABIAN CREMER}

Max Weber Foundation

cremer@maxweberstiftung.de

\section{KATRIN NEUMANN}

Max Weber Foundation 